\title{
Experimental investigation of deep drawing of C-rail benchmark using various lubricants
}

\author{
Juan Liao and Xin Xue \\ Department of Mechanical Engineering, Centre for Mechanical Technology and Automation, \\ University of Aveiro, 3810-193 Aveiro, Portugal
}

\begin{abstract}
This paper deals with the deep drawing of C-rail experimental benchmark, which has a complex deformation path. The influence of various lubricants, including the dry friction, low and high viscosity mineral oil, semisolid grease and PTFE film on the drawability of dual-phase steel sheets, was performed. The digital image correlation technique was applied for component tests as well as the deformation analysis. The drawability was experimentally assessed by comparing surface roughness, thickness reduction, and springback of drawn component. The experimental results indicate that the interfacial lubrication between tools and work-piece plays an important role on the drawability of advanced high strength steel sheets. The quality of component was improved obviously by using PTFE film compared to the other lubricants.
\end{abstract}

\section{Introduction}

A deep drawing process is one of the widely used manufacturing techniques in the automotive industry because of its capability to produce complex shapes with sheet material, often performed using lubricants to ease the forming. Lubrication is essential in deep drawing to avoid metal to metal contact and provide cooling effect by preventing heat generation and transfer during deformation. Material flow in the die cavity is influenced by frictional conditions at the die-workpiece interface. Therefore, a good understanding of the relationship of lubrication and drawalility is essential for selecting lubricants and producing good quality of sheet drawn parts.

In the past decade, many studies have been conducted on lubrication in metal forming processes via experimental method, in which the effects of lubrication on the formed quality such as fracture, wrinkling and springback are investigated in terms of individual case. Shivpuri et al. [1] investigated optimal design of spatially varying frictional constraints in reducing the risk of failure due to wrinkling and thinning. Their results showed that in the drawing of a Hishida oil pan part, an overall improvement of $33 \%$ in strain distribution can be obtained and a further $12 \%$ improvement can be obtained with probabilistic design. Reddy et al. [2] studied the effect of coefficient of friction on drawability of the metal, which are measured by limit drawing ratio and the limit strains. They concluded that the tribological aspects have profound effect in deciding the drawability of a material in deep

\footnotetext{
${ }^{a}$ Corresponding author: xin@ua.pt
}

This is an Open Access article distributed under the terms of the Creative Commons Attribution License 4.0, which permits unrestricted use, distribution, and reproduction in any medium, provided the original work is properly cited. 

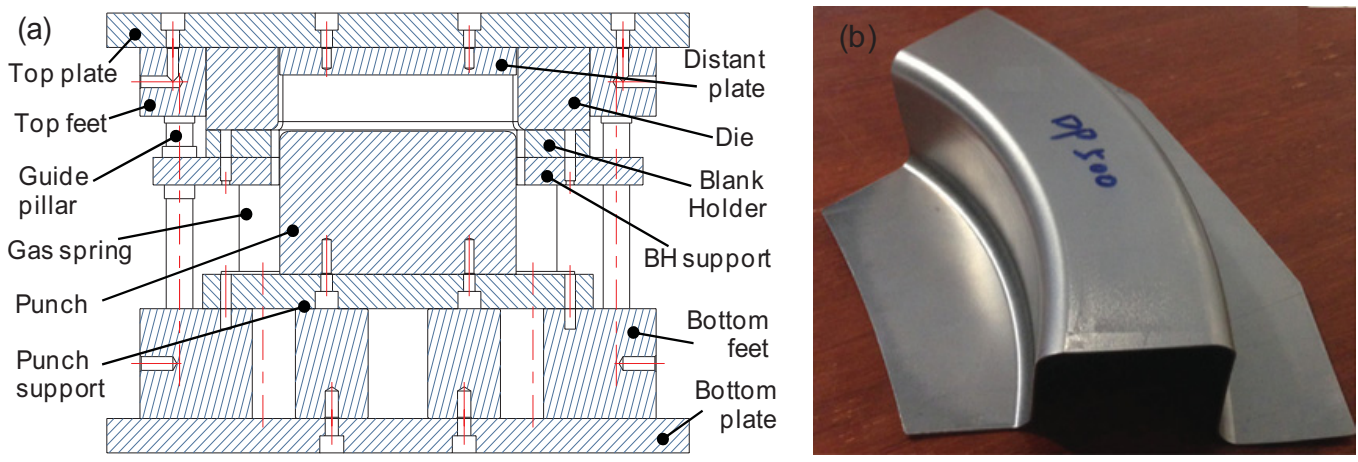

Figure 1. (a) An illustration of C-rail experimental tools (b) drawn component.

drawing processes. Masters et al. [3] compared the friction behaviour of three commercially available automotive aluminium grades, at different levels of strain, using a strip draw test. The results showed that the friction coefficient increases with the level of strain but the use of solid wax lubricants helps to overcome this maintaining a uniform friction at strains up to 10\%. For aluminium with an EDT finish the roughening effects due to plastic strain were completely overcome and again a constant friction value was valid. The above efforts provide insight into the investigation of the influence of lubrication on the drawability of C-rail benchmark, which is made of advanced high strength steel sheet (AHSS).

The present work aims to experimentally investigate the effect of lubrication on the deep drawing of AHSS sheet. First, a novel C-rail deep drawing benchmark, which has a complex loading deformation path, was developed. Second, various lubricants including low and high viscosity mineral oil, semisolid grease and PTFE film were adopted as well as the dual-phase steel (DP500) sheet. Third, the digital image correlation technique (optical 3D deformation measuring system ARGUS 5M) was applied to obtain the geometry and deformation of the formed part. Finally, the influence of lubrication on surface roughness of drawn parts, thickness reduction and springback was analysed and discussed in-depth.

\section{Experimental forming conditions}

\subsection{Deep drawing of C-rail benchmark}

A C-rail benchmark, which has a complex deformation path, was developed. Figure 1a illustrates the experimental tools, which may support a series of benchmarks corresponding to similar deep drawing geometries. Particular deformation characteristics should be induced, i.e., the shrinking and stretching metal flow on the extrados and intrados side respectively. The C-rail is a typical design for the industrial rail parts. The experimental drawn component is shown in Fig. $1 b$.

The forming parameters including the process and geometries are listed in Table 1. The forming equipment is a hydraulic press with maximum force $2500 \mathrm{kN}$. Inverse-install moving die-set is employed to reduce the vibration of the blank holder. In order to ensure accurate and robust value of blank holding force, nitrogen gas springs with the total initial force of $144 \mathrm{kN}$ are used.

\subsection{Material and lubricants}

For this work, an advanced high strength steel (AHSS) sheet (DP 500) with a thickness of $0.8 \mathrm{~mm}$ was provided by the Swedish steel company SSAB. The uniaxial tension tests in the rolling direction were performed to obtain the material parameters, and its basic mechanical properties are given in Table 2. 
Table 1. The forming parameters of C-rail deep drawing.

\begin{tabular}{|c|c|c|}
\hline No. & Forming Conditions & Values \\
\hline 1 & Total stroke of deep drawing, $\mathrm{mm}$ & 40 \\
\hline 2 & Drawing velocity, $\mathrm{mm} / \mathrm{min}$ & 180 \\
\hline 3 & Final press contact pressure, $\mathrm{MPa}$ & 10 \\
\hline 4 & Die and punch radius, $\mathrm{mm}$ & 6 \\
\hline 5 & Cross section width of punch, $\mathrm{mm}$ & 43 \\
\hline 6 & Extrados die curvature, $\mathrm{mm}$ & 150 \\
\hline 7 & Intrados die curvature, $\mathrm{mm}$ & 105 \\
\hline 8 & Maximum hydraulic press force, $\mathrm{kN}$ & 2500 \\
\hline 9 & Total force of blank holder, $\mathrm{kN}$ & 144 \\
\hline 10 & Clearance ratio & 1.125 \\
\hline
\end{tabular}

Table 2. Mechanical properties of the DP500.

\begin{tabular}{|c|c|c|c|c|c|c|c|}
\hline $\begin{array}{c}\text { Elastic } \\
\text { modulus, } \\
\mathrm{E}(\mathrm{GPa})\end{array}$ & $\begin{array}{c}\text { Poisson's } \\
\text { ratio, } \\
v\end{array}$ & $\begin{array}{c}\text { Initial yield } \\
\text { stress, } \\
\sigma_{y}(\mathrm{MPa})\end{array}$ & $\begin{array}{c}\text { Ultimate } \\
\text { tension stress, } \\
\sigma_{u}(\mathrm{MPa})\end{array}$ & $\begin{array}{c}\text { Strength } \\
\text { coefficient, } \\
K(\mathrm{MPa})\end{array}$ & $\begin{array}{c}\text { Initial } \\
\text { strain, } \\
\varepsilon_{0}\end{array}$ & $\begin{array}{c}\text { Hardening } \\
\text { exponent, } \\
\mathrm{n}\end{array}$ & $\begin{array}{c}\text { Elastic } \\
\text { modulus, } \\
\mathrm{E}(\mathrm{GPa})\end{array}$ \\
\hline 210 & 0.3 & 390 & 660 & 896 & 0.044 & 0.161 & 210 \\
\hline
\end{tabular}

Table 3. Types of lubricants and some parameters.

\begin{tabular}{|c|c|c|}
\hline No. & Lubricant types & Information \\
\hline 1 & Without lubricant & Tool surface roughness, $\mathrm{R}_{\mathrm{a}}=0.48 \sim 1.0 \mu \mathrm{m}$ \\
\hline 2 & Low viscosity mineral oil & Viscosity: $20 \mathrm{~W} 50$ \\
\hline 3 & High viscosity mineral oil & Viscosity: $40 \mathrm{~W} 80$ \\
\hline 4 & Mineral-base semisolid grease & Penetration at $25^{\circ} \mathrm{C}(0.1 \mathrm{~mm}): 265-295$ \\
\hline 5 & PTFE film & $25 \mu \mathrm{m}$ thick with one-side glue \\
\hline
\end{tabular}

Five types of lubricant condition were employed to test material formability under the same process configuration, as shown in Table 3. The average surface roughness of the initial blank sheet at the rolling direction is $\mathrm{Ra}=1.098 \mu \mathrm{m}$.

\subsection{Digital image correlation}

In this work, a non-contact optical measuring system (also known as digital image correlation DIC), was used to obtain the geometry and deformation of the formed part. The DIC technique is important to assess the deformation of the drawn parts, such as the distribution of minor and major strain, thickness reduction, shape deviation and so on. It also provides an efficient method to compare simulation and experimental results. For example, the deformation path of selected trace grid points can be obtained using this technique for the identification of the friction coefficient in the simulation model.

Grid pattern marking can be created using different methods, like laser, printing or electrolysis. The selection of the adequate method should rely on the original sheet material and specific forming process. For forming of advanced high strength steel (AHSS) sheet, the electrolytic process is a good choice because of the high blank hardness and surface contact friction. Thus, prior to forming, a regular grid pattern was marked on the surface of the initial blank by this process. As shown in Fig. 2a, standard grid distance of $2.0 \mathrm{~mm}$ and grid diameter of $1.0 \mathrm{~mm}$ were used in this work. After the forming process of the measuring object, several images were recorded with the ARGUS 5M system, in order to acquire the points positioning from different angles. For the automatic spatial orientation of the individual images, 

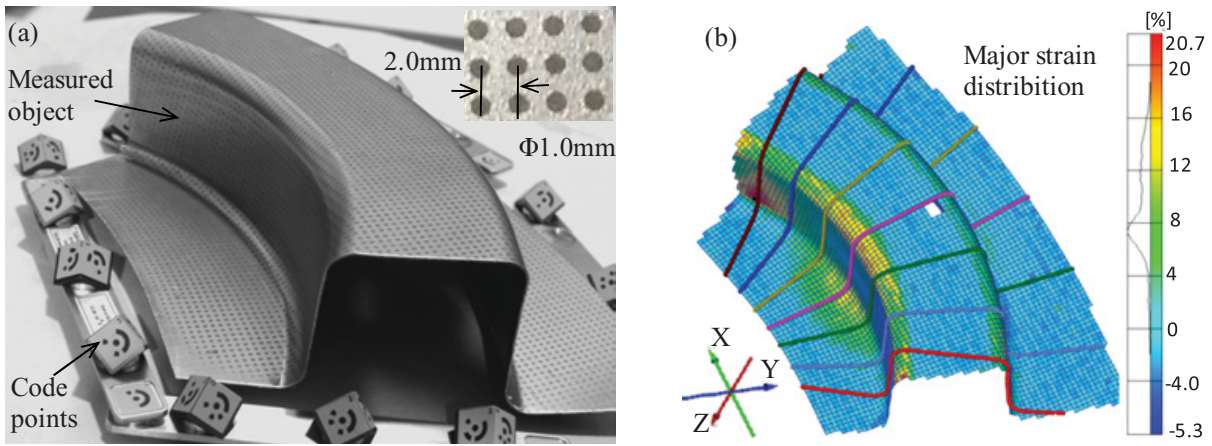

Figure 2. (a) Digital image correlation-ARGUS 3D measurement system (b) deformation analysis.

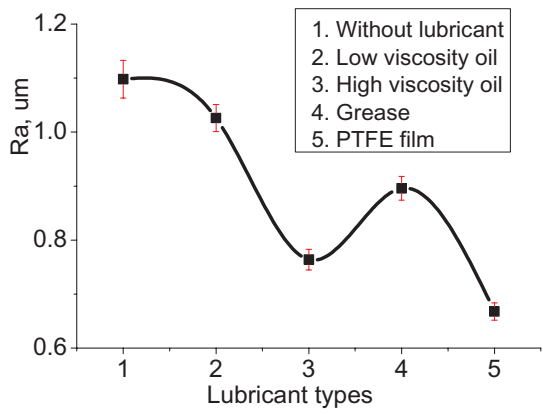

Figure 3. Sheet surface roughness after different lubricant condition forming.

calibrated objects with coded points were positioned close to (or on) the measuring object. The 3D reconstruction of the final measuring object was then obtained/computed using the photogrammetric methods included in the ARGUS software. For example, Fig. 2b shows one of measured results, namely the major strain distribution of global drawn component.

\section{Results and discussions}

\subsection{Surface roughness}

The surface roughness plays an important role on drawn parts, especially for automotive panels. Because it makes a significant effect on the surface quality such as coating and finish. In this work, SURFTEST SJ-210 MITUTOYO was used for surface roughness tests. Figure 3 shows the average surface roughness of drawn part in terms of different lubricant conditions. It can be observed that the value of surface roughness in the forming condition without lubricant is higher than other oil or film lubricants. This result is in a good agreement with the boundary regime of friction according to the Stribeck plot [4]. The other lubricants should be in the mixed regime. The higher viscosity mineral oil can produce higher surface quality of formed part. However, the grease did not produce a higher surface quality than high viscosity mineral oil, although it has also a huge viscosity. The PTFE film is a better option than other lubricants in terms of surface roughness. It also can provide more uniform lubricant on the global surface during the deep drawing process, compared to the other lubricant conditions. The only problem with PTFE film is that it is difficult to reuse after forming. This causes a high cost of mass production and is not widely used in the automotive industry. 


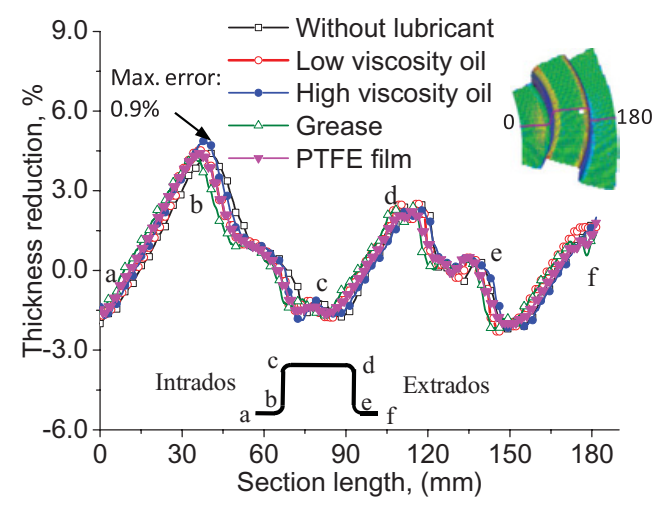

Figure 4. Comparison of Centre section of thickness reduction under various lubricants.
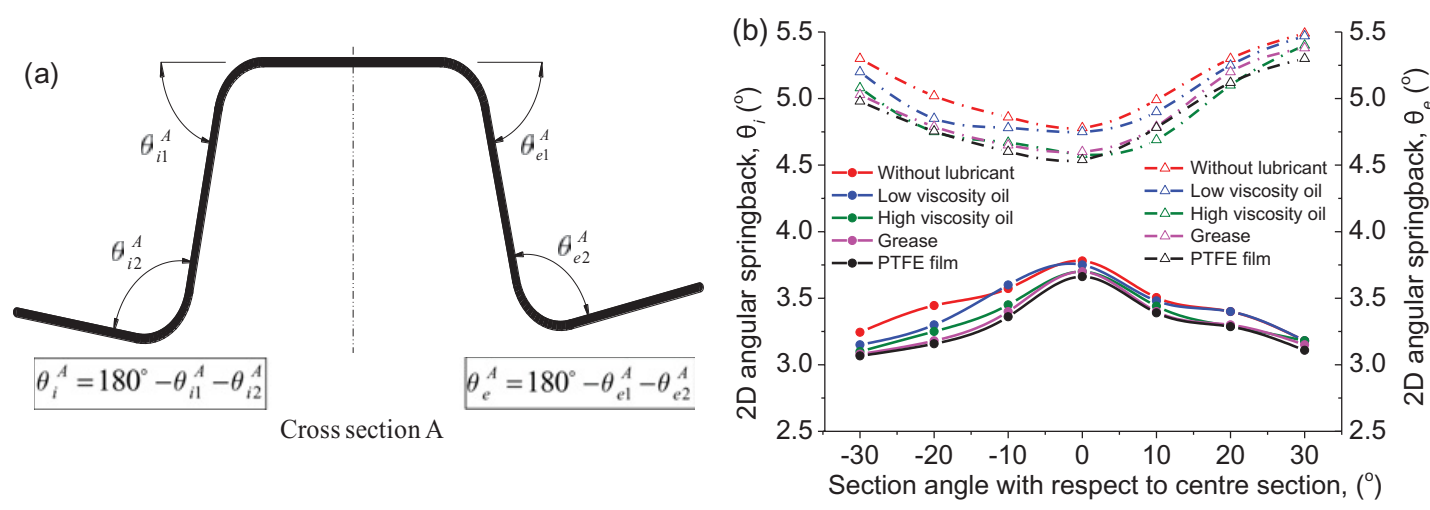

Figure 5. 2D angular springback of intrados and extrados walls: (a) schematic 2D springback of drawn part (b) comparison of $2 \mathrm{D}$ springback under different lubricants.

\subsection{Thickness reduction}

Figure 4 shows the blank thickness distribution measured in terms of center section with various lubricants. No remarkable difference was observed between the different situations. The value of the deviation is very small, almost negligible, its maximum valve being close to $1.2 \%$ at the intrados die radius. Therefore, the lubricant conditions do not seem to affect this kind of result.

\subsection{Springback}

Generally, springback refers to the undesirable part shape change that occurs upon removal of constraints after forming [5-7]. The shape deviation caused by springback always results in quality defects and difficulties during the assembly of components [7, 8]. As shown in Fig. 5a, and illustrate the 2D angular springback of the intrados and extrados walls in terms of cross section A, respectively. Figure 5b shows the $2 \mathrm{D}$ angular springback of several cross sections along the longitudinal direction. It can be observed that the 2D angular springback of the intrados walls decreases from the centre to the side section along the longitudinal direction, while the value of the extrados walls increases. Moreover, the angle of the extrados is larger than that of the intrados flange. This result also indicates that non-symmetric plastic deformation occurs in the cross sections and likely triggers twist [9]. One possible reason is that the 


\section{MATEC Web of Conferences}

intrados and extrados flanges respectively produce stretching and shrinking deformations during the deep drawing process. This causes the thickness of the extrados flange, and consequently the contact area and frictional stress, to be larger than that of the intrados flange.

From the view of lubrication, the usage of PTFE film or grease has the lowest springback than the other lubricants. In other words, the good lubrication not only provides good surface quality but also reduces the undesirable deformation, i.e., springback. This might be due to the decrease of restraining force with the better lubrication or lower friction. The frictional force caused by surface lubricant condition and pressure force plays an important role on deformation stress or strain field during the forming process.

\section{Conclusions}

In this work, various lubricants were chosen to considerably affect the material flow in the deep drawing process and were taken as key factors influencing the quality of formed part. The main conclusions of this study are as follows.

(1) The higher viscosity mineral oil can produce higher surface quality of formed part. However, the grease did not produce a lower surface quality than high viscosity mineral oil, although it has also a high viscosity. The PTFE film is a better than other lubricants in terms of surface roughness. It also can provide more uniform lubricant on the global surface during the deep drawing process, compared with the other lubricant conditions.

(2) Lubricant conditions do not seem to affect the thickness reduction of drawn part.

(3) The use of PTFE film or grease results in lower springback than the other lubricants. In other words, the good lubrication not only provides good surface quality but also reduces the undesirable deformation, i.e., springback.

The support from the Portuguese Foundation of Science and Technology (PTDC/EMS-TEC/0777/2012) and China Scholarship Council (201307920001) is greatly appreciated.

\section{References}

[1] R. Shivpuri, W.F. Zhang, Mater. Des. 30: 2043-2055 (2009)

[2] G.C.M. Reddy, P.V.R.R. Reddy, T.A.J. Reddy, Tribol. Int. 43: 1132-1137 (2010)

[3] I.G. Masters, D.K. Williams, R. Roy, Int. J. Mach. Tool. Manu. 73: 17-24 (2013)

[4] J. Hol, V.T. Meinders, H.J.M. Geijselaers, A.H.V.D. Boogaard, Tribol. Int. 85: 10-25 (2015)

[5] R.H. Wagoner, H. Lim, M.G. Lee, Int. J. Plast. 45: 3-20 (2013)

[6] J. Liao, X. Xue, M.G. Lee, J.J. Gracio, F. Barlat, Int. J. Mech. Sci. 89: 311-312 (2014)

[7] J. Liao, X. Xue, C. Zhou, J.J. Gracio, F. Barlat, Steel Res. Int. 84(5): 462-472 (2013)

[8] X. Xue, J. Liao, G. Vincze, J. Gracio, 11th International Conference on Technology of Plasticity (ICTP2014), Procedia Engineering 81: 2177-2183 (2014)

[9] X. Xue, J. Liao, G. Vincze, J. Gracio, J. Mater. Process. Tech. 216: 405-417 (2015) 